\title{
Neonatal Colorimetric Devices: Caution Against Extended Clinical Use
}

Exhaled carbon dioxide $\left(\mathrm{CO}_{2}\right)$ detection, in addition to lung inflation and increasing heart rate, is one of the most reliable methods of confirming accurate placement of an endotracheal tube during neonatal resuscitation, as reiterated in the 2015 American Heart Association Guidelines Update for Cardiopulmonary Resuscitation and Emergency Cardiovascular Care. ${ }^{1}$ Both quantitative and qualitative methods of detection are available for use in the neonatal population. Qualitative devices rely on color change in a $\mathrm{CO}_{2}$-sensitive chemical and are a popular choice among neonatal care providers. ${ }^{2}$ Historically, the first qualitative colorimetric devices used in neonates were designed for a population with body weight $>15 \mathrm{~kg}$ and had a large internal volume $(>20 \mathrm{~mL})$. When incorporated into the respiratory circuit of neonates, such devices could add significant dead space and subsequent risk of rebreathing and hypercarbia, especially with prolonged use. ${ }^{3}$ Current colorimetric devices approved for use in pediatric populations have overcome these issues by significantly reducing device internal volumes, allowing sensitive and timely detection of $\mathrm{CO}_{2}$ at the low tidal volumes seen in the neonatal population. ${ }^{4}$ The only colorimetric device labeled for use in the population with the smallest tidal volumes, the extremely low-birthweight infants with birthweight $<1$ $\mathrm{kg}$, has an internal volume of $1 \mathrm{~mL}\left(\mathrm{Neo}-\mathrm{StatCO}_{2}<\mathrm{kg}\right.$, Mercury Medical, Clearwater, Florida).

Accumulating evidence supporting the use of noninvasive respiratory support during delivery room resuscitation of premature infants has been recognized in the current American Heart Association guidelines. ${ }^{1}$ As efforts to provide adequate resuscitation in premature neonates without intubations increase, the need for objective criteria to assess effectiveness of noninvasive resuscitation modes is also being increasingly investigated. ${ }^{5-7}$ The feasibility and efficacy of exhaled $\mathrm{CO}_{2}$ devices in establishing the adequacy of noninvasive ventilation either as face mask positive-pressure ventilation or in providing CPAP, both in clinical settings and in mannequin models, have been pub-

The authors have disclosed no conflicts of interest.

Correspondence: Sagori Mukhopadhyay MD MMSc, Children's Hospital of Philadelphia Newborn Care at Pennsylvania Hospital, 800 Spruce Street, 2nd Floor, Cathcart Building, Philadelphia, PA 19107. E-mail: Mukhopadhs@email.chop.edu.

DOI: $10.4187 /$ respcare. 05046 lished. ${ }^{5,8,9}$ Although not yet officially recommended due to lack of substantial outcome data, the ease and familiarity of using colorimetric devices make them excellent candidates for further research. ${ }^{1,7}$ As the field investigates

SeE the Original Study on Page 1003

potentially prolonged use of these devices with noninvasive support, the article by Brown et $\mathrm{al}^{10}$ in this issue of RESPIRATORY CARE brings attention to a key characteristic of exhaled $\mathrm{CO}_{2}$ devices, namely their air flow resistance. In an in vitro study, the investigators measured resistance as the pressure drop to atmosphere across the device for a given applied air flow. Three available pediatric colorimetric devices and 2 capnographs were investigated over increasing flow. To provide context for the results, they similarly measured the air-flow resistance of several sizes of neonatal endotracheal tubes.

Resistance in the product inserts of the devices investigated by Brown et al, ${ }^{10}$ is depicted as back pressure generated by the device and is expressed in units of $\mathrm{cm} \mathrm{H}_{2} \mathrm{O}$ for a particular flow. Calculating the resistance in units of $\mathrm{cm} \mathrm{H}_{2} \mathrm{O} / \mathrm{L} / \mathrm{s}$ generates the values shown in Table 1, which provides better visualized comparisons for the values generated by Brown et al. ${ }^{10}$ We have added the specifications of the Stat- $\mathrm{CO}_{2}$ (Mercury Medical, Clearwater, Florida), a device labeled for use in a population with body weight $>15 \mathrm{~kg}$, to provide context for the interplay between device internal volume and resistance. The resistance for each device was calculated by the investigators at increasing flow and clearly illustrates the rising resistance of devices with falling internal volume and rising flow (Fig. 1 in Brown et $\mathrm{al}^{10}$ ). Not surprisingly, the highest resistance was seen in the device with the smallest internal volume. Although the device specifications for this product list resistance at $5 \mathrm{~L} / \mathrm{min}$ flow, Brown et $\mathrm{al}^{10}$ report the resistance with $10 \mathrm{~L} / \mathrm{min}$ flow, a flow commonly used in usual clinical care. The mean resistance obtained was $61.1 \mathrm{~cm}$ $\mathrm{H}_{2} \mathrm{O} / \mathrm{L} / \mathrm{s}$, which is significantly elevated compared with other colorimetric devices in their study.

The authors note that designing $\mathrm{CO}_{2}$ colorimetric devices requires ensuring a certain contact time between the chemical and the exhaled air, which involves either adding dead space or slowing the passage of the exhaled air. Because newer devices have reduced dead space, it seems 


\section{EDITORIALS}

Table 1. Comparable Variables in Manufacturer Specifications and Findings of Brown et al ${ }^{10}$

\begin{tabular}{|c|c|c|c|c|c|}
\hline \multirow[b]{2}{*}{ Device } & \multicolumn{4}{|c|}{ Manufacturer Specifications } & \multirow{2}{*}{$\begin{array}{c}\mathrm{R}, \mathrm{cm} \mathrm{H}_{2} \mathrm{O} / \mathrm{L} / \mathrm{s} \\
\text { Measured by } \\
\text { Brown et al }{ }^{10}\end{array}$} \\
\hline & $\begin{array}{c}\text { Internal } \\
\text { Volume, } \mathrm{mL}\end{array}$ & $\begin{array}{l}\text { Labeled } \\
\text { for, } \mathrm{kg}\end{array}$ & $\begin{array}{l}\text { Flow, } \\
\text { L/min }\end{array}$ & $\begin{array}{c}\mathrm{R}, \mathrm{cm} \\
\mathrm{H}_{2} \mathrm{O} / \mathrm{L} / \mathrm{s}\end{array}$ & \\
\hline Neo-stat & 1 & $0.25-6$ & 10 & NA & 61.1 \\
\hline Neo-stat & 1 & $0.25-6$ & 5 & 36 & 31.1 \\
\hline Pedi & 3 & $1-15$ & 10 & 15 & 9.9 \\
\hline Mini & 3 & $1-15$ & 10 & 15 & 8.4 \\
\hline Nihon-K & 1.8 & $2-7$ & 10 & 4.8 & 2.6 \\
\hline Emma & 1 & $<10$ & 10 & 6 & 7.1 \\
\hline Stat- $\mathrm{CO}_{2}$ & 25 & $>15$ & 60 & 3 & NA \\
\hline
\end{tabular}

that increased contact time was achieved by slowing the exhaled air, possibly contributing to the increased resistance, illustrated by the authors in Figure $4^{10}$ in the multiple small holes through which the exhaled air is required to pass.

The consequences of such high resistance are appropriately noted by the authors. Some of these devices technically perform for up to $24 \mathrm{~h}$, allowing the option for continued use, for example, during transport of intubated neonates. However, if unaccounted for, additional resistance has the potential to cause increased work of breathing and ultimately fatigue, de-recruitment, and atelectrauma. The authors provide context for the amount of resistance in the highest-resistance device by comparing it with a 3.0 endotracheal tube. In a way, this suggests that such resistance can be corrected for and managed within a ventilator system. However, if this device were to be applied to spontaneously breathing infants receiving CPAP or other forms of noninvasive ventilation, the additional resistance, if not anticipated, could result in deterioration of respiratory distress with prolonged use.

Although the study highlights an important variable that may not be routinely anticipated and accounted for in clinical practice, the study has some limitations. It is an in vitro study, and the investigators use a simplified method for measuring resistance. Previous exhaustive studies have demonstrated that air flow resistance through a conduit is highly influenced by dynamic effects on the air flow profile due to entrance and exit conditions (eg, sudden changes in tube diameter as well as by the turbulent vs laminar nature of the airstream ${ }^{11,12}$ ). Further, it has been shown that, under certain conditions, air flow resistance with oscillatory flows tends to be lower than resistance measured with a steady flow. ${ }^{13}$ Use of a lung model utilizing commonly used airway tubing and adaptors and ventilated with a sinusoidal flow waveform to more realistically mimic in vivo conditions may have resulted in resistance measures more accurately approximating what an actual infant would experience. The authors recognize the need for clinical studies to measure the actual impact of such resistance. Until such studies are available, it seems prudent to avoid prolonged clinical use of neonatal colorimetric devices without accounting for the high reported in vitro resistance.

Sagori Mukhopadhyay MD MMSc Neonatology

Children's Hospital of Philadelphia Perelman School of Medicine University of Pennsylvania Philadelphia, Pennsylvania

Emidio Sivieri MSE Neonatology Children's Hospital of Philadelphia Philadelphia, Pennsylvania

\section{REFERENCES}

1. Wyckoff MH, Aziz K, Escobedo MB, Kapadia VS, Kattwinkel J, Perlman JM, et al. Part 13: neonatal resuscitation: 2015 American Heart Association guidelines update for cardiopulmonary resuscitation and emergency cardiovascular care. Circulation 2015;132(18 Suppl 2):S543-S560.

2. Hawkes GA, Kenosi M, Ryan CA, Dempsey EM. Quantitative or qualitative carbon dioxide monitoring for manual ventilation: a mannequin study. Acta Paediatr 2015;104(4):e148-e151.

3. Bhende MS, LaCovey D. A note of caution about the continuous use of colorimetric end-tidal $\mathrm{CO}_{2}$ detectors in children. Pediatrics 1995; 95(5):800-801

4. Garey DM, Ward R, Rich W, Heldt G, Leone T, Finer NN. Tidal volume threshold for colorimetric carbon dioxide detectors available for use in neonates. Pediatrics 2008;121(6):e1524-e1527.

5. Kong JY, Rich W, Finer NN, Leone TA. Quantitative end-tidal carbon dioxide monitoring in the delivery room: a randomized controlled trial. J Pediatr 2013;163(1):104-108.e1.

6. Finer NN, Rich W, Wang C, Leone T. Airway obstruction during mask ventilation of very low birth weight infants during neonatal resuscitation. Pediatrics 2009;123(3):865-869.

7. Hawkes GA, Kelleher J, Ryan CA, Dempsey EM. A review of carbon dioxide monitoring in preterm newborns in the delivery room. Resuscitation 2014;85(10):1315-1319.

8. Leone TA, Lange A, Rich W, Finer NN. Disposable colorimetric carbon dioxide detector use as an indicator of a patent airway during noninvasive mask ventilation. Pediatrics 2006;118(1):e202-e204.

9. Hawkes GA, Kenosi M, Finn D, O’Toole JM, O'Halloran KD, Boylan $\mathrm{GB}$, et al. Delivery room end tidal $\mathrm{CO}_{2}$ monitoring in preterm infants $<32$ weeks. Arch Dis Child Fetal Neonatal Ed 2016;101(1): F62-F65.

10. Brown MK, Lazarus DV, Gonzales SR, Rich WD, Wozniak MJ, Poeltler $\mathrm{DM}$, et al. Resistance of colorimetric carbon dioxide detectors commonly utilized in neonates. Respir Care 2016;61(8):1003-1007.

11. Wright PE, Marini JJ, Bernard GR. In vitro versus in vivo comparison of endotracheal tube airflow resistance. Am Rev Respir Dis 1989;140(1):10-16.

12. Loring SH, Elliott EA, Drazen JM. Kinetic energy loss and convective acceleration in respiratory resistance measurements. Lung 1979; 156(1):33-42.

13. Chang HK, Mortola JP. Fluid dynamic factors in tracheal pressure measurement. J Appl Physiol Respir Environ Exerc Physiol 1981; 51(1):218-225. 